\title{
Article
}

\section{Nice and Tidy: translation and representation}

Temple, Bogusia

Available at http://clok.uclan.ac.uk/3582/

Temple, Bogusia (2005) Nice and Tidy: translation and representation. Sociological Research Online.

It is advisable to refer to the publisher's version if you intend to cite from the work.

For more information about UCLan's research in this area go to http://www.uclan.ac.uk/researchgroups/ and search for < name of research Group>.

For information about Research generally at UCLan please go to http://www.uclan.ac.uk/research/

All outputs in CLoK are protected by Intellectual Property Rights law, including Copyright law. Copyright, IPR and Moral Rights for the works on this site are retained by the individual authors and/or other copyright owners. Terms and conditions for use of this material are defined in the policies page.

\section{CLoK}

Central Lancashire online Knowledge www.clok.uclan.ac.uk 
Nice and Tidy: Translation and Representation

\author{
by Bogusia Temple \\ University of Salford \\ Sociological Research Online, Volume 10, Issue 2, \\ < http://uww.socresonline.org.uk/10/2/temple.htm/> \\ doi:10.5153/sro. 1058
}

Received: 22 Jul 2004 Accepted: 1 Mar 2005 Published: 30 Jun 2005

\begin{abstract}
Across many disciplines, including sociology, anthropology, philosophy, cultural studies and sociolinguistics, writers and researchers are concerned with how language is used to construct representations of people in written and oral accounts. There is also increasing interest in cross-disciplinary approaches to language and representation in research. Within health, social care and housing research there is a rapidly growing volume of writing on, and sometimes with, people whose first language is not English. However, much empirical research in these fields remains at the level of 'findings' about groups of people with the issue of how they are represented remaining unexamined. In this article I discuss some of the different ways researchers have looked at issues of translation and representation across languages. As I show, some researchers have attempted to ignore or by-pass these issues in their research, some have given up the task as impossible and others have attempted the impossible. I argue that, although there can be no single 'correct' way for researchers to represent people who speak different languages, choices about how to do this have epistemological and ethical implications.
\end{abstract}

\title{
Keywords: Language; Minority Ethnic Communities; Representation; Translation; Reflexivity.
}

\section{Introduction}

1.1 Across many disciplines, including sociology, anthropology, philosophy, cultural studies and sociolinguistics, writers and researchers are concerned with how language is used to construct representations of people in written and oral accounts. The work of Foucault (1972), Derrida $(1976,1987)$, Barthes (1977), Smith (1982), Bourdieu (1991), Spivak (1992), Bhabha (1994), Hall (1997) and Roberts (2001) forms just a small sample of this literature. There is also increasing interest in cross-disciplinary approaches to language and representation in research. For example, Coupland, Sarangi and Candlin (2001) and Munday (2001) discuss the value of cross-disciplinary research in relation to sociolinguistics. They argue that there is now an 'intellectual climate that is, more than ever, open to the theoretical interchange between linguistic and social research' (p. xvi). Within health, social care and housing research there is a rapidly growing volume of writing on, and sometimes with, people whose first language is not English. For example, in housing research, Harrison with Phillips (2003) provide a useful overview of some of this research. However, much empirical research in these fields remains at the level of 'findings' about groups of people with the issue of how they are represented remaining unexamined. The links to the literature cited above are rarely made.

1.2 However, choosing to engage or not with language difference is an epistemological, political and ethical decision. Some researchers have argued this has always been the case (Spivak 1992; Roberts 2001). For example, Roberts cites examples of socio- or anthropological linguists who have long been concerned with 'the politics of representation' (p.329). She argues that:

Critical social theory helps us to be reflexive about our methods. But perhaps whether we turn the reflexive searchlight on to issues of transcription, interview methods or any other social science methods, it is as much a matter of bringing our politics of social justice into our work as making strong links between it and social theory... a reflexive politics can come from engagement in the field as much as from imported theory (2001, p. 329).

1.3 The local context of production and the history of interaction are important for the researcher (p. 331). The current focus on language as a measure of fitness for naturalisation makes the point in a way that is 
1.4 Issues of representation are present in all research. In cross language research the languages themselves form part of the context of interpretation and Spivak (1992) has shown that the relationship between languages forms part of the process of constructing meaning (see below). This relationship, she argues, should form part of the debate about representation. As cross-language research grows academics are employing interpreters, translators and researchers if they can't speak the relevant languages themselves.

1.5 Increasingly researchers are working with people who speak languages other than English who interpret for them, carry out interviews and focus groups, and provide written English accounts of the research. In most cases research ends up in written form, with or without an acknowledgement of how language differences were treated. In all cases the written account is influenced by everyone involved in the research, whether they actually wrote the final text or not (see below). In this sense everyone involved in the research is present within it and has 'authored' the written text. In this article I focus on translation issues.

Developments within this field, particularly within translation studies (Venuti 1993/2000), have helped me to think about the different ways in which it is possible to carry out cross language research generally and the consequences of choosing a particular method. Some of the issues apply to concerns over representation in interpretation. Further work on the differences between the transmission of written and oral accounts across languages and the effects on how people are represented would be extremely valuable.

1.6 I discuss some of the different ways researchers have looked at issues of translation and representation across languages. As I show, some researchers have attempted to ignore or by-pass these issues in their research, some have given up the task as impossible and others have attempted the impossible. Although there can be no single 'correct' way for researchers to represent people who speak different languages, choices about how to do this have epistemological and ethical implications.

\section{Translation and representation}

2.1 Researchers from a range of disciplines, including sociolinguists, anthropologists and writers in translation studies, have shown that there can be no single correct translation of a text (see for example Overing 1987; Simon 1996). These views start from an epistemological position that has been described in the social sciences in various ways, including deconstructionist, social constructionist and interpretative (see Derrida 1976 and 1987, Harding 1987, Alcoff 1991 for discussions of these positions and Temple 1997, Edwards 1998, and Venuti 1995 and 1998 for discussions within translation and interpretation). This epistemological position acknowledges that all researchers present accounts from their own social location and there is no way to make 'objective' knowledge claims from outside of your position in the social world. All research therefore involves issues of representation, as discussed by authors such as Silverman (1987), Derrida (1976; 1987), Alcoff (1991), Gilroy (1997), Hall (1997) and Hertz (1997) and all choices of method have epistemological consequences. This is the position I take in this article.

2.2 In relation to translation, many researchers have taken up this stance. Simon (1996) sums up well the position that all translation is conditional:

The solutions to many of the translator's dilemmas are not to be found in dictionaries, but rather in an understanding of the way language is tied to social realities, to literary forms and to changing identities. Translators must constantly make decisions about the cultural meanings which language carries, and evaluate the degree to which the two different worlds they inhibit are "the same". These are not technical difficulties, they are not the domain of specialists in obscure or quaint vocabularies. They demand the exercise of a range of intelligences. In fact the process of meaning transfer has less to do with finding the cultural inscription of a term than in reconstructing its value (pp. 137 -138).

2.3 The work of Spivak (1992, 1993/2000) and Venuti $(1995,1998)$, amongst others, demonstrates that language is not neutral and translation is an act that creates a world that is presented from the author's position within it. They develop the argument that current translation practice is generally to try to remain faithful to English language structures and encourages the use of an English baseline that silences alternative ways of constructing the social world through language. For example, Venuti $(1995,1998)$ argues for sending the reader abroad by what he calls 'foreignization' of texts rather than standard translation practice that 'domesticates' and tames texts for English readers. In a similar way, Spivak (1993/2000) argues:

In the act of wholesale translation into English there can be a betrayal of the democratic ideal into the law of the strongest. This happens when all the literature of the Third World gets translated into a sort of translatese, so that the literature by a woman in Palestine begins to 
2.4 She sets up a politics of translation to examine the relationships between languages within texts to tease out the ways in which 'translatese' occurs. She argues that what can seem resistant in English may be reactionary in the original language. The examples she gives come from the attempt to translate 'gender' into Bengali (1992, p. 186) and into the US feminist context. She argues that 'the history of the language, the history of the author's moment, the history of the language-in-and-as-translation, must figure in the weaving [of the translation] as well' (p. 184).

2.5 This stance is similar to that of Roberts (2001) and her 'politics of representation' (see above). However, few researchers working across languages within the housing, health and social care fields have taken these points on board either in relation to how they carry out the interviews or how they then translate the accounts into English. This is the case even when they are taking a position that is sympathetic to the need to acknowledge different perspectives. Although spurred on by government pronouncements to be inclusive and consult service users, the baseline of language difference is still rarely addressed. Such research is presented as if there are no translation issues and no differences in concept construction and meaning across languages (see for example Karn et al. 1999 and Steele 1999).

2.6 Researchers within housing, health and social care have tackled issues of representation in cross language translation in a number of ways. I examine three approaches here: non-recognisition or dismissal of representational issues (there is no problem); a recognition of issues of representation and a position that argues these cannot be tackled by people who don't speak or write the relevant languages (there is no point); and an attempt to tackle the issues by situating the translator within the text (have a look at what we did). None of these approaches can 'solve' the issues around representation for reasons I discuss below. They all, however, are ethical as well as epistemological choices.

\section{The language by-pass: there's no problem}

3.1 This approach has a number of variations. One is particularly prominent in much health, housing and social care research, including in the recently rapidly expanding literature on refugee people seeking asylum. People who speak little or no English are included in research but the issue of language is ignored or seen as a technical concern (see for example Karn et al 1999; Steele 1999; Hyndman and WaltonRoberts 2000; Khanum 2001; Chenoweth and Burdick 2001). There is no attempt within the research to discuss whether there are possible differences in word or concept meaning. People from language communities are employed as interpreters to transmit words across languages or as researchers to do the interviews themselves, translate them and then pass the English version to the researchers. Issues around representation and language are not addressed.

3.2 In such research, there are two aspects of representation that are ignored. First, there is the question of whose perspective on concepts is being used. The researcher, even though they may speak the relevant language, cannot represent a whole community. In the social sciences the 'insider - outsider' issue of representation has been widely debated. There is little similar debate about the position of interpreters or 'community researchers' (I discuss this in more detail below). Secondly, this kind of research neglects the importance of the written text in research. The very act of writing has been shown to change how a communication is presented and received (Derrida 1976, 1987; Oates 1999; Temple and Young 2004).

3.3 Treating translation as just a case of 'accurate' transmission of meaning where issues can be resolved as the level of technique ignores all this work. Researchers have suggested that techniques such a back translation and the use of professional translators (see for example Esposito 2001; Pham and Harris 2001) can be used to check whether a translation is 'correct'. The problem with this is the wealth of research that shows that there are many words that the translator can choose to select from and the 'same' words may have different connotations across languages (see below and in-depth critical evaluation by Edwards 1998).

3.4 Some researchers recognise that there may be issues of representation in cross language interpretation and translation and try to by-pass these by not including anyone who cannot speak/read/write English in the research (see for example Kopinak 1999; NHS Executive 2001; Bissell, May and Noyce 2004). The final written text is literally a reflection of the complete absence of anyone who cannot present who they are or what they think in English. Even though the research is presented as including people from minority ethnic communities, only people within these communities who can register on the researcher's own language radar can take part in the research. In this kind of work, there is no need for interpreters and translators. The national survey of NHS patients' views of general practice in 1998 (NHS Executive 2001) was a postal questionnaire and the authors argue that the bias resulting from the exclusion of a small number of non-English speakers is likely to be very small P.10). However, they report that fewer than half of people whose usual language was not English found the GP easy to understand (p95). Statistical bias is not the only issue here. Using such data to describe the current state of people's views on the NHS limits, 
by definition, evaluation to a very English language baseline. Researchers have shown that people from minority ethnic communities do not think services are appropriate to their needs (see Robinson 2002 for a review of the literature). The kind of approach suggested by researchers who only speak to other English speakers is unlikely to lead to appropriate service development for everyone.

3.5 The study by Bissell, May and Noyce (2004) of 'people of Pakistani origin who speak English' is another example of brushing language and representation issues under the carpet. The authors acknowledge that language issues may affect their research and argue that they by-pass them by including only English language speakers. However, this 'solution' ignores the views of whole sections of communities who do not speak English on service development and raises ethical concerns in a similar way to the work of the NHS Executive (2001) discussed above. It also assumes that fluency in a language is irrelevant as merely speaking English ensures the same baseline for definition of concepts. Only speaking and writing up accounts from people the researchers can understand does not absolve them from the need to investigate the role of language in constructing concepts and words. The issue still remains: there may be differences in the use and role of the English language between people whose preferred language of communication is English and people who choose to use English. For example, given that Bissell, May and Noyce are looking at models of health care interaction, will everyone in their sample recognise the term 'drug' or 'pharmacist' or 'care' in the same way whatever their language preference? The researchers are representing a particular account of 'people of Pakistani origin' that is based on a view that the languages they speak will not matter in that account. Researchers have suggested, however, that:

Whilst participants may be able to communicate effectively in a second language for much of the time, the extra effort required, especially when emotional or sensitive topics are involved, can result in impoverished accounts .....as well as making the grounded accuracy and value of the data uncertain....Researchers have found that when interviewees speak in a second language they perceive themselves as less confident, happy and intelligent...(Murray and Wynne, 2001, pp. 158-159).

3.6 This research suggests that language ability may affect the way people can present themselves to researchers. It may also affect the way they are perceived and represented by researchers in written accounts (see below). Meanings are not tied to languages but research has shown that different concepts may have different meanings according to language group. Concepts such as 'sheltered housing' (Ratcliffe 1996) and 'social care' (Temple, Glenister and Raynes 2002) may have different connotations in different languages. The basic concepts used in a research project need to be investigated or the researcher cannot begin to understand what responses are about (see here also Wilson and Revauger 2001). Moreover, only using English as the medium of research is both colonial and unethical (Spivak 1992, 1993/2000; Venuti 1995, 1998).

\section{The language outsider cannot know: there is no point}

4.1 The research I discuss here is an exemplar of a reasoned epistemological and ethical position on representational issues in cross language research and one that is built on the epistemological position discussed above in which language is recognised as important. In her research with childless women in India, Riessman (1993) takes on board the view that how something is said is as important as what is said. However, she argues that in this particular research, as she is unable to speak the language and can't reproduce the its structure in her written text she will not try:

Attention to certain formal aspects of language - precisely how something is said and lexical choice - requires verbatim materials in the speaker's language. Instead I create structures from the interview texts to convey the sense l've made. A kind of textual experimentation, I use poetic stanzas (groups of lines about a single topic) and other units of discourse...as rhetorical devices to make my analysis of the organisation of a story clear for the reader (2000, p. 131).

4.2 She uses this textual experimentation to make clear that this is her way of constructing the written account. This approach is built on the view that there is no single correct way to write or read a written account. All translation is a joint production between the author, the interpreter and the reader. Riessman worked with an interpreter in the interviews but produced her own written version of the interview rather than employing the interpreter as a researcher/translator in her own right. This does not mean that the choice she made was any less preferable on epistemological grounds: her choice reflected her desire to carry out the interviews herself and to make her role in the research, and in particular the structure of the written account, clear.

4.3 However, approaching this from a perspective such as that of Spivak (1992; 1993/2000) and Venuti (1995, 1998), it could be argued that Riessman's choice smacks of colonialism and domestication of texts 
in a way that hides differences based on the languages used. The fallback position is always English or American English and that is the point of the work of Venuti and Spivak. The structure and presentation of the words of a woman, here from India, read as if she is American. Riessman (2004) did not choose, for example, to discuss any issues around concept definition or perspective with her interpreter before she carried out the research or during the research process. Presenting her written account as her own perspective without active engagement with others involved in producing the research closes down alternative perspectives, defining them out of the terms of reference from the start. The end result is similar to that of the language by-pass model in that only the researcher's meanings and perspective are centred.

4.4 Moreover, research with minority ethnic communities and women, amongst others, also raises questions about any kind of drive to limit engagement to 'insiders only', including language insiders. Issues of representation cannot be solved by introducing particular categories of people who can or cannot represent others. Apart from the dangers of only engaging with people you consider to be like yourself, extreme arguments, Twine (2000) posits, for or against matching 'rest on an implicit model that characterizes all researchers as either absolutely inside or outside homogeneous sociocultural style' (p. 9). Twine also documents the foundationalist assumptions of uncritical 'insider' statements. All researchers make value judgements about the people involved in their research on the basis of criteria such as social class, age, gender, sexuality, race and other factors as well as language. Twine argues that insider status generates its own barriers and difference may stimulate rather than block communication by focusing on taken for granted understandings. Insiders and outsiders, according to Twine, generate different kinds of knowledge rather than any one producing better knowledge (p. 13). Moreover, there is a danger in assuming that particular views are attached to a social category: 'Racial subordination does not mechanistically generate a critical stance vis-a-vis racism any more than colonialism created anticolonial subjectivities' ( $p$. 15).

4.5 Twine's arguments are worth spelling out here as they apply equally to all arguments that only particular people can carry out research, or alternatively that they cannot (for example see Hammersley's 1995 views on the 'bias' of politically motivated research that rests on the argument that there is a neutral position from which to carry out research that excludes 'the insider'). Taking Twine's work on board, setting up imaginary language insiders and outsiders re-introduces the divide between 'correct' and 'wrong' translations via the back door. People defined as language outsiders can still engage in debate about meanings and perspectives during, as well as after, the writing up process and even language insiders are not immune from accusations that they do not represent all sections of communities.

4.6 I go on now to look at how researchers have tried to address the work of writers such as Venuti (1995, 1998) and Spivak (1992) who bring to the surface a politics of translation in an attempt to foreignize texts in the move away from what are seen as colonialist writings.

\section{Situating the translator within the text: look at what we did}

5.1 This approach can be summed up as an acceptance of the impossibility of achieving a single correct version of a cross language interview and the attempt to make clear the context of the interview and the written account produced of it. This approach has similarities with that of Riessman (2000). There is no objective definitive text. However, there is a difference in the 'solution' proposed by researchers who situate all parties within accounts as suggested by postcolonial writers such as Spivak (1992) and Venuti (1995). Riessman, as discussed above, gives up any attempt to re-produce the structure of the account or to discuss perspectives with the interpreter. She argues that as she produced the written account and did not know the language any attempt to re-produce its structure or other lexical devices would not be appropriate. She does acknowledge the role of the interpreter but does not engage with how she interpreted what they heard until after she had written her account and was re-assessing her position.

5.2 Recently Riessman has acknowledged that her views on her interviews have changed, partly by discussing them with the interpreter (Riessman 2004). However, this is not throughout the research, only at the end when she was writing up in English. The starting point is still solely that of the researcher. The interpreter is part of the production process but still not involved in the debate on perspective. We know nothing about her views on the topic. This strategy leaves the researcher open to accusations of colonialisation and ignores the politics of translation. This is easier to do when the default position is AngloAmerican.

5.3 Other researchers have attempted to actively engage interpreters and translators during the research process (Temple 1997, Edwards 1998; Temple and Edwards 2002). For example, Edwards (1998) uses the concept of interpreters/translators as 'key informants' and advocates a reflective evaluation of social location, values and beliefs and an understanding of the relationship between the researcher and people taking part in research. Temple (1997) similarly uses the concept of 'intellectual auto/biographies' (Stanley 1990): 
an analytic (not just descriptive) concern with the specifics of how we come to understand what we do, by locating acts of understanding in an explication of the grounded contexts these are located in and arise from (p.62).

5.4 Neither researcher is arguing that interpreters/translators perspectives should be privileged, rather that they should be included as active in the research process and that their contributions to the final product should be acknowledged. Simon (1996) and Venuti (1998) argue that the conditions under which translators are employed have an impact on the work they produce. They are seen as not 'original' and therefore technicians rather than authors in their own right. They are often women paid for discrete pieces of work where they are not even acknowledged or named in the final written text. Their structural/social position informs their translation in the words that they choose to convey concepts but their influence on the text is marginalized and often ignored. Temple and Edwards both recognise the effects of this relative imbalance in the authority of the author and translator/interpreter as author and use their approach to bring them out from behind the shadows, even if it is for only a brief moment until the academic researcher takes over again.

5.5 Both Temple and Edwards also problematise issues of representation and recognise that here is no one to one match between a translator's position within their culture and within their translation (see here Simon 1996; Temple 2002). Questions about whose views are being represented in a translation surface again. Translators are by definition bilingual and attributing their views to a community or tying meaning to language is highly problematic. Within communities there are differences of perspective and picking one person to represent a whole community is problematic. The employment of community researchers, key workers, and bi-lingual workers in service development and research per se does not solve issues of representation but raises questions about how that person was chosen, whom they represent and how accountable they are (Temple 2002). Twine's (2000) points about the difficulties of attributing insider and outsider positions are again relevant here.

5.6 As argued by Venuti (1998) issues of representation can still surface when the researchers/translators have actively tried to foreground them in their writing. Many editors and researchers insist on 'tidying up the quotes' when some researchers are using such 'untidiness' to as a tool to signify difference. An example of this is Esposito's (2001) work in which she argues that professional interpreters/translators are preferable and back translation can be used to test accuracy and 'truth-value (p. 577). This approach falls under the language by-pass model (see above). She states that texts should 'sound as natural as possible' (p.571). The example given in her text suggests that natural means English-American. The importance of hesitation and interruptions in flow that are common in everyday speech are taken out and grammar tidied up to make everyone seem very confident and able to speak BBC English. The point of keeping in the breaks in the flow of the conversation may be to show that not everyone uses the same language base and there are epistemological consequences in such tidying up. The translations that researchers use, including those of Edwards and Temple, are neat and tidy and in the act of using language to discuss difference they reintroduce the English baseline via the backdoor of 'tidying up' and following grammatically 'correct' English language strcutures.

5.7 Venuti's (1998) work on the domestication of text and the role of the academy and publishers in how translation is approached is relevant here:

The popular aesthetic requires fluent translations that produce the illusory effect of transparency, and this means adhering to the current standard dialectic while avoiding any dialectic, register or style that calls attention to words as words and therefore pre-empts the reader's identification. As a result, fluent translation may enable a foreign text to engage a mass readership....But such a translation simultaneously reinforces the major language and its many other linguistic and cultural exclusions while masking the inscription of domestic values. Fluency is assimilationist, presenting to domestic readers a realistic representation inflected with their own codes and ideologies as if it were an immediate encounter with a foreign text and culture (1998, p. 12).

5.8 Venuti aims to send the reader abroad. He argues that translators should flaunt their partiality instead of concealing it (1995, p34). He calls for resistancy where the text is non-fluid or estranging in style and is designed to make the translator visible. His translation project seeks to emphasize identity and ideological stance. He states that 'the point is to use a number of minority elements whereby one invents a specific, unforeseen, autonomous becoming' (p.11). Esposito's (2001) calls for 'natural' sounding 'accurate' texts would represent an attempt at extreme domestication.

5.9 Arguably, none of positions discussed in this paper achieve this, including those of Temple (1997) and Edwards (1998) who ultimately sanitise and domesticate presentation so that everyone 'reads' the same. The many versions of translations that are discussed with translators are narrowed to one version with 
words/concepts presented as if there were no choices to be made. Alternative words and explanations of choices are not given for readers to discuss.

5.10 Some translators try to open up texts by showing the original language quote or presenting alternative translations for readers to choose from, rather than trying to position the translator in the text. For example, Spivak (1992) and Venuti (1998) try to foreignize their texts, and open up debates about other possible translations, by providing accounts in the original languages with their translations by the side. Alternative readings then become possible, but only for people who can read in those languages. However, debates about perspective and the effects of editorial practices still remain.

5.11 There is also evidence that researchers cannot control what a text represents as the reader and listener is also active in constructing meaning (Venuti 1998, Smith 1982,Derrida 1976, 1987). As all translators construct identities of 'others' for domestic audiences within text (Venuti 1998) there is an issue here about readership and possible re-enforcement of negative stereotypes when translators choose to foreignize texts with different styles and non-English grammatical practices (see here discussion by Standing 1998 on what happens to how people are 'seen' in accounts that are not tidied up). This is well illustrated in the field of interpretation by the work of Sandra Hale (1998). She found that court interpreters constantly altered the style of witnesses' answers, ether favourably or detrimentally, thus potentially changing the outcome of the case. Style is important and using hedges and fillers such as 'you know' may be important for evaluating witness credibility in that they give an impression of vagueness.

5.12 Translators (and academics generally) tidy up accounts and change how we see people. Not doing so may make people look incoherent and 'shady'. We all paint a picture of people with the words we use and even though we cannot determine the way readers will read our accounts we have to be aware of the dangers of re-enforcing stereotypes. Readers expect written accounts to be logical, consistent and well thought out, whilst oral exchanges do not have to live up to these strictures (Oates 1999). Whilst thwarting some expectations by trying to 'foreignize' written accounts, issues of representation remain.

\section{Conclusion}

6.1 I have presented some of the issues around translation and representation and how researchers have attempted to address them. Issues around representation are present in all research. When different languages are involved ignoring these differences raises further ethical, political and epistemological problematics. I have argued that all choices about whether or how to include speakers of other languages in research have epistemological consequences, even though these cannot be 'solved' using any method of cross language research.

6.2 Which approach a researcher chooses is in some measure influenced by the resources they have and by academic and publishing traditions. As Venuti (1998) are argued persuasively both academic life and the publishing world effect how research is produced. The assumption is that there is an 'original' author and a translator who is faithful to the author's intentions. The translator is not seen as an active author of a written account. A 'correct' and tidy translation is important in publishing. In research the translator's task is again seen as remaining faithful to the 'original', but not so faithful as to overturn the privileged status of the language of English. Researchers who try to break out of this mould are restrained by these limits. Their solution is often to present what is seen as likely to be accepted in the arena they are writing for and to leave methodological debates for a separate occasion. Other language speakers influence their perspective but this is often only noted when the methodology is discussed and directly addressed elsewhere.

6.3 Researchers have used a variety of approaches to writing texts about people who speak languages other than their own. Some researchers have chosen to work only with people who can speak English, whatever community they come from and they see no need to address how they represent others in a language they may not prefer to use. There are also a great number of research reports where the authors do research with non English speakers but do not engage at all with the possibility that people may use language in a way that differs from their own use. Others argue for accurate translations as the solution. Some researchers feel they are not able to bring out certain characteristics within texts in other languages and therefore are up front about only presenting their own meanings. However, increasingly, researchers are debating representation within their translations using a variety of means, for example, foreignization, situating translators within texts and providing text with the original language alongside.

6.4 Venuti describes the aim of an ethics of translation as being 'to alter reading patterns, compelling a not unpleasurable recognition of translation among constituencies who, while possessing different cultural values, nevertheless share a long-standing unwillingness to recognize it' (1998, p13). The aim of such an approach is to 'decenter the domestic terms that a translation project must inescapably utilize' (p. 82). He argues that 'this is an ethics of difference that can change the domestic culture' (p. 82). This plea for a recognition of difference is why I prefer to engage in debates about translation rather than ignore 
representational issues or dismiss them as insoluble and therefore give up trying. It is a view of translation that is based on a decision to try to discuss possible differences in meaning across languages. This is an ethical and epistemological position.

\section{References}

ALCOFF, L. (1991) 'The problem of speaking for others', Cultural Critique, Vol. 20, pp. 5 - 32.

BARTHES, R. (1997) Image - Music - Text: Essays Selected and Translated by Stephen Heath. Glasgow: Fontana/Collins.

BHABHA, H. (1994) The Location of Culture. London: Routledge.

BOURDIEU, P. (1991) Language and Symbolic Power. London: Polity Press.

BISSELL, P., May, C. \& Noyce, P. (2004) 'From compliance to concordance: barriers to accomplishing a reframed model of health care interactions', Social Science \& Medicine, Vol. 58, No. 4, pp. 851 - 862.

CHENOWETH, J. \& Burick, L. (2001) 'The Path to Integration: Meeting the Special Needs of Refugee Elders in Resettlement', Refuge, Vol. 20, No. 1, pp. 20 - 29.

COUPLAND, N., Sarangi, S. \& Candlin, C. (editors) Sociolinguistics and Social Theory. London: Longman. CRICK REPORT (2003) Life in the United Kingdom. Report of the advisory group on citizenship. London: Home Office.

DERRIDA, J. (1976) Of Grammatology. Baltimore: John Hopkins University Press.

DERRIDA J. (1987) The Post Card: From Socrates to Freud and Beyond. Chicago: The University Of Chicago Press.

EDWARDS, R. (1998) 'A critical examination of the use of interpreters in the qualitative research process', Journal of Ethnic and Migration Studies, Vol. 24, No. 2, pp. 197 - 208.

ESPOSITO, N. (2001) 'From Meaning to Meaning: The Influence of Translation Techniques on Non-English Focus Group Research', Qualitative Health Research, Vol. 11, No. 4, pp. 568 - 579.

FOUCAULT, M. (1972) The Archaeology of Knowedge. London: Tavistock.

GILROY, P. (1997) 'Diaspora and the detours of identity' in Kathryn Woodward (editor) Identity and Difference. London: Sage Publications and The Open University.

HALE, S. (2002) 'How faithfully do court interpreters render the style of non-English speaking witnesses' testimonies? A data-based study of Spanish-English bilingual proceedings', Discourse Studies, Vol. 4, No. 11 , pp. $25-47$.

HALL, S. (1997) (ed.) Representation: cultural representations and signifying practices. London: Sage and The Open University.

HAMMERSLEY, M. (1995) The Politics of Social Research. London: Sage.

HARDING, S. (editor) (1987) Feminism and Methodology. Milton Keynes: Open University Press.

HARRISON, M. with Philips, D. (2003) Housing and Black and Minority Ethnic Communities: Review of the Evidence Base. London: Office of the Deputy Prime Minister.

HERTZ, R. (editor) (1997) Reflexivity \& Voice. London: Sage Publications.

HYNDMAN, J. \& Walton-Roberts, M. (2000) 'Interrogating borders: a transnational approach to refugee research In Vancouver', The Canadian Geographer, Vol. 44, No. 3, pp. 244 - 258.

KARN, V., Mian, S., Brown, M. \& Dale, A. (1999) Tradition, Change and Diversity: Understanding the Housing Needs of Minority Ethnic Groups in Manchester. London: The Housing Corporation.

KOPINAK, J. (1999) The Health of Bosnian Refugees in Canada, Ethnicity \& Health, Vol. 4, No.1-2, pp. 65 82. 
MUNDAY, J. (2001) Introducing Translation Studies: Theories and Applications. London: Routledge.

MURRAY, C. \& Wynne, J. (2001) Researching community, work and family with an interpreter, Community, Work \& Family, Vol. 4, No. 2, retrieved online 19/07/04

NHS EXECUTIVE (2001) National Surveys of NHS patients: General Practice 1998. London: Department of Health.

OATES, D. (1999) 'Talking Texts: Issues of Translation in Research' in Mark Banting, Jane Elliott, Min Dongchao, Debbie Oates and Bogusia Temple (editors) Inside the Translation Machine. Manchester: University of Manchester.

OVERING, J. (1987) 'Translation as a creative process: the power of the name' in L. Holly (editor) Comparative Anthropology. Oxford: Basil Blackwell.

PHAM, T. \& Harris, R. (2001) 'Acculturation strategies among Vietnamese-Americans', International Journal of Intercultural Relations, Vol. 25, No. 3, pp. $279-300$.

RATCLIFFE, P. (1996) ' 'Race' and housing In Bradford: addressing the needs of the South Asian, African and Caribbean communities' Bradford, Bradford Housing Forum.

RIESSMAN, C. (1993) 'Narrative Analysis', Qualitative Research Methods, Vol. 30. pp. 1 - 78.

RIESSMAN, C. (2000) ' "Even if We Don't Have Children [We] Can Live": Stigma and Infertility in South Indian Narrative and the Cultural Construction of Illness and Healing', in C. Mattingly \& L. Garro (editors) Narrative and the Cultural Construction of IIIness and Healing. Berkeley, CA and London : University of California Press.

RIESSMAN, C. (2004) 'Emotions, Misunderstandings, and the Shaping of Interpretation: Looking Back on a Case Study', Paper presented at the $4^{\text {th }}$ Annual Narrative, Memory and Everyday Life Conference, University of Huddersfield.

ROBERTS, C. (2001) ' 'Critical' social theory: Good to think with or something more?' in N. Coupland, S. Sarangi, \& C. Candlin (editors) Sociolinguistics and Social Theory. London: Longman.

ROBINSON, M. (2002) Communication and Health in a Multi-Ethnic Society. Bristol: Policy Press.

SILVERMAN, D. (1987) Communication and Medical Practice. London: Sage.

SIMON, S. (1996) Gender in Translation: Cultural Identity and the Politics of Transmission . Routledge: London \& New York.

SMITH, D. (1982) The Active Text. Paper presented at the Tenth World Congress in Sociology, Mexico City.

SPIVAK, G. (1992) 'The politics of translation' in M. Barrett \& A. Philips (editors) Destabilising theory: Contemporary feminist debates. Cambridge: Polity Press.

SPIVAK, G. (1993/2000) 'The politics of translation', in L. Venuti (editor) The Translation Studies Reader. Routledge: London.

STANDING, K. (1998) 'Writing the Voices of the Less Powerful: Research on Lone Mothers, in Jane Ribbens \& Rosalind Edwards (editors) Feminist Dilemmas in Qualitative Research: Public Knowledge and Private Lives. London: Sage Publications.

STANLEY, L. (1990) 'Moments of writing: Is there a feminist auto/biography?', Gender \& History, Vol. 2, pp. $58-67$.

STEELE, A. (1999) 'A study of the housing and social care needs of older people from the black and minority ethnic communities in Derby', Salford: University of Salford.

TEMPLE, B. (1997) 'Issues in translation and cross-cultural research', Sociology, Vol. 31, No. 3, pp. 607 618.

TEMPLE, B. (2002) 'Crossed Wires: Interpreters, translators and bilingual workers in cross language research', Qualitative Health Research, Vol. 12, No. 6, pp. 844 - 854.

TEMPLE, B. \& Edwards, R. (2002) 'Interpreters/Translators and Cross-Language Research: Reflexivity and 
Border Crossings', International Journal of Qualitative Methods , Vol. 1, No. 2, Article 1,

$<$ http://www.ualberta.ca/ ijqm/>.

TEMPLE, B., Glenister, C., \& Raynes, N. (2002) 'Prioritising home care needs: research with older people from three minority community groups', Health and Social Care in the Community, Vol. 10, No. 3, pp. 179 186.

TEMPLE, B. \& Young, A (2004) 'Qualitative research and translation dilemmas', Qualitative Research, Vol. 4, No. 2, pp. $161-178$.

TWINE, F. (2000) 'Racial Ideologies and Racial Methodologies', in F. Twine \& J. Warren (editors) Racing Research, Researching Race: Methodological Dilemmas in Critical Race Studies. New York: New York University Press.

VENUTI, L. (1993/2000) The Translation Studies Reader. Routledge: London.

VENUTI, L. (1995) The Translator's Invisibility: A History of Translation . London: Routledge.

VENUTI, L. (1998) The Scandals of Translation: Towards an ethics of difference . London: Routledge.

WILSON, G. \& Revauger, J. (2001) 'Special Issue', Social Research Methodology: Theory and Practice, Vol. 4, No. 4, pp. 259 - 338. 